Published in final edited form as:

J Public Health Manag Pract. 2015 ; 21(6): E19-E22. doi:10.1097/PHH.000000000000214.

\title{
Training Public Health Advisors
}

\author{
Pamela A. Meyer, PhD, Kristin M. Brusuelas, MPH, Daniel J. Baden, MD, and Heather L. \\ Duncan, MPH \\ Field Services Office (Drs Meyer and Baden and Ms Brusuelas) and Public Health Associate \\ Program (Ms Duncan), Office for State, Tribal, Local and Territorial Support, Centers for Disease \\ Control and Prevention, Atlanta, Georgia.
}

\begin{abstract}
Federal public health advisors provide guidance and assistance to health departments to improve public health program work. The Centers for Disease Control and Prevention (CDC) prepares them with specialized training in administering public health programs. This article describes the evolving training and is based on internal CDC documents and interviews. The first federal public health advisors worked in health departments to assist with controlling syphilis after World War II. Over time, more CDC prevention programs hired them. To meet emerging needs, 3 major changes occurred: the Public Health Prevention Service, a fellowship program, in 1999; the Public Health Associate Program in 2007; and integration of those programs. Key components of the updated training are competency-based training, field experience, supervision, recruitment and retention, and stakeholder support. The enduring strength of the training has been the experience in a public health agency developing practical skills for program implementation and management.
\end{abstract}

\section{Keywords}

public health advisor; public health training; public health worker

Federal public health advisors (PHAs) provide guidance and assistance to health departments and other health organizations to improve public health program work and ensure that program activities are consistent with national goals and objectives. ${ }^{1}$ A PHA assigned to a health department is physically located there and is typically involved in the day-to-day operations of public health programs. ${ }^{1}$ Public health advisors translate science into practice by using their program operations and management knowledge and skills to implement public health programs. ${ }^{2}$ For decades, they helped shape the delivery of essential public health services.

\footnotetext{
Correspondence: Pamela A. Meyer, PhD, Field Services Office, Office for State, Tribal, Local and Territorial Support, Centers for Disease Control and Prevention, Century Center Bldg 1825, MS E70, Atlanta, GA 30329, (pmeyer@cdc.gov).

The authors recognize the contributions of Glen Koops, Louise Galaska, and John Lisco for historical context, and Michelle Scott and Michele Mercier, for current program content accuracy.

The findings and conclusions in this report are those of the authors and do not necessarily represent the official position of the Centers for Disease Control and Prevention.

None of the authors report conflicts of interest.
} 
The Centers for Disease Control and Prevention (CDC) has been providing specialized training in the principles, practices, methods, and techniques of administering public health programs required for PHAs. However, no journal articles have described this training. This article describes the evolving training of PHAs to meet emerging needs and is based on 1 book, ${ }^{2}$ several internal CDC documents, and interviews with PHAs and training staff.

\section{Historic Training}

After World War II, the federal government introduced the Public Health Program Specialist Job Classification Series, which included the PHA, a major specialization, ${ }^{1}$ and hired and assigned PHAs to work in health departments to assist with controlling syphilis. ${ }^{3}$ These workers learned how syphilis prevention and control programs operated and developed skills in organizing and implementing public health programs. The early PHAs relocated to different health departments every few years, allowing them both to gain broad perspectives on how public health is practiced in different health departments and how varied political structures, priorities, and access to resources affect programs and to share the practical approaches they learned.

Over time, other CDC prevention programs, such as the Tuberculosis Elimination Program and the Immunization Program, hired PHAs. To ensure that their roles, recruitment, and training were meeting emerging public health needs, the CDC reviewed the existing training's ability to develop additional skills (eg, analysis and consultation), rapidly teach skills for mid- and senior-level jobs, instill knowledge of new public health strategies and prevention of infectious as well as noncommunicable diseases, and improve worker recruitment and development. ${ }^{4}$ The findings in the 1996 Bales and Bradford ${ }^{4}$ report helped launch the Public Health Prevention Service, a fellowship program. Although it used the PHA as its prototype, there were several substantial differences. It was a fellowship program and its trainees were referred to as fellows who upon graduation could be hired not only as PHAs but also as health scientists or health education specialists depending on their education. The new fellowship program provided uniform crosscutting formal instruction to develop skills in broad topics such as leadership, management, and program evaluation. Minimum eligibility requirements were higher: a master's degree and at least 1 year of paid public health work experience. Another distinction was exposure to multiple programs in its 3 -year training. Fellows spent their first year at the CDC gaining skills/knowledge and hands-on experience in various topic areas and learning how the CDC operates. In their second and third years, fellows worked in 1 host site leading project planning, implementation, and evaluation. Host sites were often state or local health departments, but could also be other health organizations, or academia.

By 2005, the number of PHAs assigned to health departments had declined $60 \%$ over a $12-$ year period, ${ }^{5}$ due to fewer full-time employee positions in the field and no agencywide policy for staffing or replacing them. An internal CDC white $\operatorname{paper}^{6}$ reported a greater percentage of CDC field staff at the mid-career level, with far fewer available to provide basic service. To renew the frontline service delivery focus and to meet the need for a continuous source of field-tested workers who understand the delivery of public health services at all levels, the CDC created the Public Health Associate Program (PHAP) in 
2007, with Florida piloting the program and 5 other states joined the next year, contributing to the design and ensuring greater utility and sustainability. Associate Program trainees, referred to as associates, are provided skills necessary to qualify for an entry-level PHA or similar position upon graduation. Associates' activities were typically supportive, such as managing cases and assisting with outbreak investigations.

\section{Training New PHAs}

In January 2014, the CDC announced that the fellowship program would end with the class graduating in 2015. The PHAP will continue to train and provide experiential learning to early career professionals who contribute to the public health workforce. However, some unique aspects of the fellowship program that can enhance the Associate Program are being considered for adoption. One that has been adopted from the fellowship program is the liaison committee. The liaison committee comprises current associates who provide input to CDC PHAP staff to improve the program. One of the fellowship program's training offerings under consideration is the optional third-year practicum to help provide more specialized training. Key components of this updated program are competency-based training, field experience, supervision, recruitment and retention, and stakeholder support.

\section{Competency-based training}

The CDC designs the training curriculum, in consultation with scientific program experts and health departments, to support associates' experiential learning, reinforce program competencies, and enhance professional growth and development. Competencies are periodically reviewed and updated and are adapted from the broad model published by the Council on Linkages Between Academia and Public Health Practice. ${ }^{7}$ CDC training staff review position descriptions for entry-level PHAs and select competencies that will help graduates develop the skills needed to compete for those positions. In addition, key stakeholders such as CDC programs, host sites, and academia provide input on competency selection by identifying skills needed for successful work in the field. The CDC offers an annual in-person orientation for new associates and competency-based training for first- and second-year associates. In-person training is supplemented by distance-based learning opportunities provided by the CDC as well as on-site training provided by the host site.

\section{Field experience}

During their 2-year field assignments, associates have typically worked in 2 different CDCsponsored program areas such as the Tuberculosis Elimination Program in the first year and Injury Prevention Program the next. Assignments are tailored to meet local public health service delivery needs, support the specialized work of the CDC categorical program funding the associate, and foster associate competency development through the field assignment activities. Daily work at the host site is planned, organized, and directed to support skill development in the following areas: analysis and assessment, communication, program planning, cultural competency, partnership and collaboration, public health practice, financial planning, interpersonal skills, and community relationship building. 
During the first year at their host site, associates learn and apply disease prevention and health promotion methods, such as disease and health hazard investigation and implementation of interventions, public health education and promotion, and other aspects of public health program operations. Both the CDC and the host site offer didactic training on topics that support the hands-on activities. They learn the structure and function of public health programs, participate in delivering basic program services, and gain competence in the technical elements of carrying out program activities at the local level. The CDC selects host sites based on the site's ability to provide supervision and appropriate work assignments for the trainee. Their assignments become progressively more varied and complex throughout the year to expose them to a wider range of public health service delivery processes and activities.

\section{Supervision}

CDC supervisors ensure that associates meet training requirements; host site supervisors oversee their onsite public health practice activities. CDC supervisors provide overall supervision of associates and collaborate with host site supervisors to ensure that training requirements are achieved. Both CDC and host site supervisors periodically discuss the associates' performance and progress toward meeting competencies. Each associate has a Performance Management Appraisal Plan that states the outcomes and performance objectives for which they are accountable. CDC supervisors also serve as a support and programmatic resource for the host site supervisors. Associates are assigned a CDC mentor, who helps them learn to acclimate to the field work environment, achieve work-life balance, develop career plans, and know how federal, state, and local governments function and collaborate. Mentors are mid- to upper-level career CDC employees with at least 6 years of CDC experience and commit to mentoring associates throughout the 2-year program.

\section{Recruitment and retention}

Recruitment efforts target academic institutions with a high minority enrollment of Native Indian/Alaskan Native and Hispanic student populations to address the need for a more diverse public health workforce to represent and meet the needs of a diverse nation. ${ }^{8,9}$ The CDC interviews qualified applicants to assess essential interpersonal skills, such as effective communication, and ability to navigate effectively through difficult job situations. CDC programs identify and encourage qualified health departments to apply to be a host site. Host site selections are based on the site's ability to provide appropriate work assignments and a rich learning environment that offers experience in delivering and supporting public health activities and interventions with appropriate supervision for the associate.

Health departments may hire graduates directly. Some CDC programs hire graduates for positions at CDC offices or as assignees at health departments. In addition, some CDC programs offer graduates an opportunity for extended hire through a practicum and some later permanently hire graduates as regular employees or contractors.

\section{Stakeholder support}

Success and sustainability of developing this field-tested public health workforce require sharing responsibilities among key stakeholders. Host sites make a substantial in-kind 
commitment by providing on-site supervisors who directly supervise and guide associates and provide tailored on-the-job training. CDC programs are responsible for disease-specific training in the field, supervise specific assignments, provide mentors, sponsor and fund associates' salaries, hire graduates, and provide input into training development by identifying current and emerging needs. In July 2014, the CDC convened the first meeting of the PHAP Stakeholder Engagement Workgroup to increase stakeholder input in training and curriculum design and communications. This workgroup has representatives from all major stakeholder groups including CDC programs, National Association of County \& City Health Officials, Association of State and Territorial Health Officials, host sites, alumni groups, and academia. CDC leadership has been increasing year 1 enrollment from 50 in 2010 to 134 in 2013 and 145 in 2014. The CDC Director's goal is to hire 200 year 1 associates in 2015 .

\section{Future Directions}

Since its inception, the PHA training has adapted and evolved to prepare this public health workforce to meet new challenges. Consequently, PHAs have been successfully used in a multitude of roles. The enduring strengths of the training have been the experience in a public health agency developing practical skills for program implementation, facilitation and management, and flexibility. The future workforce will continue to need skills and knowledge in the traditional areas such as program management, epidemiology, and field investigation as well as new areas such as informatics and public health and health care collaboration and coordination. This training and the workforce it prepares will continue to be essential to help advance CDC's mission.

\section{REFERENCES}

1. US Office of Personnel Management. [Accessed December 28, 2014] Position Classification Standard for Public Health Program Specialist Series, GS-0685. TS-47. https://www.opm.gov/ policy-data-oversight/classification-qualifications/classifying-general-schedulepositions/standards/ 0600/gs0685.pdf. Published November 1980.

2. Myerson, BE.; Martich, FA.; Naehr, GP. Ready to Go. The History and Contributions of US Public Health Advisors. Research Triangle Park, NC: Social Health Association; 2008.

3. Centers for Disease Control and Prevention. Public Health Associate Program (PHAP). [Accessed November 19, 2014] About PHAP. http://www.cdc.gov/phap/about.

4. Bales, VS.; Bradford, W. Develop Public Health Program Specialist. Atlanta GA: Centers for Disease Control and Prevention; 1996.

5. McKing Consulting Corp.. Review of the GS-685: A Public Health Advisor Series. Final Report. Atlanta, GA: McKing Consulting Corporation; 2005.

6. Koops, G. CDC's Field Workforce: A Component of the Extramural Investment Portfolio. Portfolio Management Project. Atlanta, GA: Centers for Disease Control and Prevention; 2005.

7. Public Health Foundation. Council on Linkages Between Academia and Public Health Practice. Overview. http://www.phf.org/programs/council/Pages/default.aspx.

8. Hilliard TM, Boulton ML. Public health workforce research in review. Am J Prev Med. 2012; 42(5S1):S17-S28. [PubMed: 22502923]

9. Crawford CA, Summerfelt WT, Roy K, Chen A, Meltzer DO, Thacker SB. Perspectives on public health workforce research. J Public Health Manage Pract. 2009; (suppl):S5-S15. 